\section{Efficient Photocatalytic Hydrogen Evolution by Iron Platinum Loaded Reduced Graphene Oxide}

\author{
S. E. Moradi" \\ Young Researchers and Elite Club, Islamic Azad \\ University-Sari Branch, Sari, Iran
}

doi: 10.15255/CABEQ.2015.2222

Original scientific paper

Received: April 28, 2015

Accepted: February 23, 2016

In this work, graphene oxide (GO) was prepared by the Hummers method from natural graphite, and modified with iron and platinum nanoparticles by the solvothermal method. The structural order and textural properties of the grapheme-based materials were studied by BET, TEM, XRD, TG-DTA, and XPS techniques. UV-Vis diffuse reflectance spectra indicate the band gap for FePt and FePt-rGO composites to be 3.2 and $2.8 \mathrm{eV}$, respectively. FePt-rGO showed a hydrogen generation rate higher than that of the FePt nanoparticles. A detailed study of Pt effect on the photocatalytic $\mathrm{H}_{2}$ production rates showed that Pt NPs could act as an effective co-catalyst, enhancing photocatalytic activity of FePt-rGO. The FePt-rGO gave a $\mathrm{H}_{2}$ production rate of $125 \mu \mathrm{mol} \mathrm{g}^{-1} \mathrm{~h}^{-1}$. This is ascribed to the presence of Pt NPs (acting as electron sinks) and graphene oxide (as an electron collector and transporter) in FePt-rGO composites.

Key words:

hydrogen evolution, reduced graphene oxide, photocatalysis, platinum nanoparticle, iron nanoparticle

\section{Introduction}

The production of hydrogen (as a clean energy carrier that could replace fossil fuels) nowadays attracts much attention because of environmental pollution and energy demands ${ }^{1-3}$. Recently, hydrogen evolution technologies, such as production by steam reforming ${ }^{4}$, electrolysis ${ }^{5}$, degradation of organic pollutants in wastewater ${ }^{6}$, and photoelectrochemical splitting of water ${ }^{7}$ have been investigated. Among all the methods, photocatalytic hydrogen generation processes $^{8-10}$ on nanomaterials have gained considerable attention because of their ability to provide a clean and renewable energy source.

Photocatalytic splitting of water promises to be a cleaner and greener route towards generation of hydrogen. A key challenge for water splitting is the development of catalysts for the direct and efficient production of hydrogen from protons. Up to now, numerous metal-based photocatalysts have been discovered as catalysts for this reaction ${ }^{11,12}$, but they are ultimately of low efficiency, high cost, and low abundance $^{13,14}$. Several strategies have been employed to improve the photocatalytic performance of metallic photocatalysts, for example, textural design $^{15,16}$, coupling with other metal photocatalysts ${ }^{17,18}$, etc. In particular, great interest has been devoted to linking carbon nanomaterials ${ }^{19}$. Conjugated carbon materials, such as fullerenes, graphene,

"Corresponding author: Seyyed Ershad Moradi,

e-mail: er moradi@hotmail.com; Tel.: 98-11-33314785 carbon nanotubes, and graphite are excellent candidates for refining the transport of photocarriers during photocatalysis through the formation of electronic interactions with photocatalyst nanoparticles. Among carbon-based materials, graphene has been reported as an efficient co-catalyst for photocatalytic $\mathrm{H}_{2}$ production because of its high specific surface area (theoretical value $2600 \mathrm{~m}^{2} \mathrm{~g}^{-1}$ ), excellent electron mobility $\left(15000 \mathrm{~m}^{2} \mathrm{~V}^{-1} \mathrm{~s}^{-1}\right.$ at room temperature), thermal conductivity, and high mechanical strength $^{20-22}$. In recent years, reduced graphene oxide ( $\mathrm{rGO}$ ) has been modified with different nanoparticles, such as $\mathrm{ZnO}^{23}, \mathrm{TiO}_{2}{ }^{24}$ and $\mathrm{CdS}^{25}$. They have been used as photocatalysts under visible-light irradiation. Previously, a few shape-controlled Pt alloy nanocrystals, such as Pt-Fe and $\mathrm{Pt}-\mathrm{Co}^{26}$, have been made using diols and other reducing agents. To the best of our knowledge, metals like Pt and Fe play a significant role in the hydrogen evolution process, especially when they are combined with carbon-based composites ${ }^{27-30}$.

Herein, we have attempted to introduce the grapheme-based composite as a novel class of photocatalysts for enhancement of photocatalytic hydrogen evolution. In this work, we have synthesized platinum-iron NPs loaded reduced graphene oxide using $\mathrm{Pt}(\mathrm{acac})_{2}$ and $\mathrm{Fe}(\mathrm{acac})_{3}$ as metal nanoparticle sources. We have also examined the photocatalytic activity of FePt-rGO and FePt nanomaterials for the water splitting reaction to produce hydrogen in the presence of methanol as a sacrificial agent. 


\section{Experimental}

\section{Materials}

Graphite powder (<20 micron) was purchased from Sigma-Aldrich (St. Louis, MO, USA) and used as received. $\mathrm{H}_{2} \mathrm{SO}_{4}(>99 \%)$, hydrochloric acid (AR grade), $\mathrm{H}_{2} \mathrm{O}_{2}\left(30 \%\left(\mathrm{w} \mathrm{v}^{-1}\right)\right), \mathrm{KMnO}_{4}(>99 \%)$, Platinum acetylacetonate $(\mathrm{Pt}(\mathrm{acac}), 97 \%)$ ), iron acetylacetonate $(\mathrm{Fe}(\mathrm{acac}), 99.9 \%)$, and ethylene glycol (EG) were all purchased from Sigma-Aldrich (St. Louis, MO, USA).

\section{Synthesis of GO adsorbent}

GO was synthesized from expandable graphite using a modified Hummers' method $^{31}$. An amount of $1 \mathrm{~g}$ of graphite powder was added to $23 \mathrm{~mL}$ of concentrated $\mathrm{H}_{2} \mathrm{SO}_{4}$ in an ice bath. $\mathrm{KMnO}_{4}(3 \mathrm{~g})$ was then added slowly with stirring and cooling to keep the temperature of the reaction mixture below $293 \mathrm{~K}$. The temperature of the reaction mixture was increased and maintained at $308 \mathrm{~K}$ for 30 minutes. When $46 \mathrm{~mL}$ of deionized water was added slowly to this mixture, the temperature was increased to $371 \mathrm{~K}$. After 15 minutes, $140 \mathrm{~mL}$ of deionized water was added followed by $10 \mathrm{~mL}$ of $30 \% \mathrm{H}_{2} \mathrm{O}_{2}$ solution. The solid product was separated by centrifugation. It was washed repeatedly with $5 \% \mathrm{HCl}$ solution until the sulfate ions had been removed, and then washed with distilled water repeatedly until free of chloride ions. The product was then filtered and washed 3-4 times with acetone to make it moisture-free, and the residue dried in an oven at $338 \mathrm{~K}$ overnight. The GO was suspended in water and exfoliated by ultrasonication for 3 hours.

\section{Synthesis of FePt-rGO composites}

FePt-rGO was obtained by the method as described by Chen et al. $^{32}$ Prior to the synthesis of FePt-rGO, the as-prepared GO was dispersed in deionized water by ultrasonication (KQ-50B supersonic cleaner, Kun Shan Ultrasonic Instruments Co., Ltd, China; ultrasonic frequency: $40 \mathrm{kHz}$; ultrasonic power: $80 \mathrm{~W}$ ) for 3 hours. FePt-rGO composites were synthesized by the solvothermal method using ethylene glycol (EG)-water as the solvent. In a typical synthesis, $\mathrm{Pt}(\mathrm{acac}){ }_{2}(0.25 \mathrm{mmol}, 0.0985 \mathrm{~g})$ was dissolved in EG (15 mL) under magnetic stirring with a short heating $\left(90-100{ }^{\circ} \mathrm{C}, 5 \mathrm{~min}\right) . \mathrm{Fe}(\mathrm{a}-$ cac) $)_{3}(0.25 \mathrm{mmol}, 0.0883 \mathrm{~g})$ was dissolved in another $15 \mathrm{~mL}$ of EG under magnetic stirring with a short heating period (below $100{ }^{\circ} \mathrm{C}$ ), which was subsequently added dropwise into the EG solution containing $\mathrm{Pt}(\mathrm{acac})_{2}$. Then, $10 \mathrm{~mL}$ of $\mathrm{GO}\left(5 \mathrm{mg} \mathrm{mL}^{-1}\right)$ aqueous dispersion was added dropwise into the EG solution. After 30 minutes of stirring, the mix- ture was transferred to, and sealed in, a 50-mL Teflon-lined stainless steel autoclave, and heated to $160{ }^{\circ} \mathrm{C}$ for $24 \mathrm{~h}$, and then cooled to room temperature. The precipitate was collected and washed alternately with ethanol and deionized water by centrifugation $(10,000 \mathrm{rpm}, 5 \mathrm{~min})$, and then dried at $60{ }^{\circ} \mathrm{C}$ in vacuum.

\section{Characterization and hydrogen evolution}

The morphology and surface structure of GO and FePt-rGO were examined by X-ray diffraction (XRD, Philips Xpert MPD, Co K $\alpha$ irradiation, $\left.\lambda=1.78897 \mathrm{~A}^{\circ}\right)$, and the X-ray photoemission spectroscopy (XPS) analysis was acquired by using a Scienta ESCA 200 analyzer (Gammadata, Sweden) equipped with a monochromatized $\mathrm{Al} \mathrm{Ka}$ X-ray source. Transmission electron microscope (TEM) analysis was conducted with a JEM 2100 transmission electron microscope (JEOL, Japan) at $200 \mathrm{kV}$. The composition and thermal properties of GO and FePt-rGO were determined by TGA with a PL Thermal Sciences; model PL-STA using a heating rate of $10 \mathrm{~K} \mathrm{~min}^{-1}$ from room temperature to $1073 \mathrm{~K}$. The measurements were conducted using approximately 3-mg samples, and then weight retention/temperature curves were recorded.

Volumetric nitrogen sorption studies were taken at $77 \mathrm{~K}$ using a Micromeritics ASAP 2020 system. Before performing the measurements, the samples were degassed below $1.33 \mathrm{~Pa}$ at $90{ }^{\circ} \mathrm{C}$ for $1 \mathrm{~h}$ and heated $\left(10{ }^{\circ} \mathrm{C} \mathrm{min}^{-1}\right)$ to $350{ }^{\circ} \mathrm{C}$ for $10 \mathrm{~h}$. The specific surface area (SBET) was calculated by the BET method in the relative pressure range of 0.04-0.20. Total pore volume $(V)$ was calculated at relative pressure $p / p_{0}=0.98$. The microporous volume $\left(V_{\text {mi }}\right)$ was determined by applying Dubinin-Radushkevich (DR) analyses on the corresponding isotherms in the relative pressure range $10^{-4}-10^{-2}$. The volume of pores smaller than $1 \mathrm{~nm}(V<1 \mathrm{~nm})$ was determined by the cumulative pore volume in the relative pressure range $10^{-6}-10^{-4}$ using the Horvath-Kawazoe (HK) method. The meso- and micropore sizes of samples were analyzed by the Barrett-Joyner-Halenda (BJH) and HK methods, respectively. A Shimadzu spectrophotometer (Model 2501 PC) was used to record the UV-Vis diffuse reflectance spectra of the samples with the region of 200 to $800 \mathrm{~nm}$.

The photocatalytic hydrogen evolution tests were carried out at room temperature under atmospheric pressure in a closed quartz reactor system. The light intensity was measured to be $80 \mathrm{~mW} \mathrm{~cm}^{-2}$ by an optical power meter (1 L, $1400 \mathrm{~A}$, International Light) from a $400 \mathrm{~W}$ high-pressure $\mathrm{Hg}$ lamp with a water filter to remove the infrared part of the spectrum. Typically, the photocatalysts $(5 \mathrm{mg})$ were suspended in an aqueous methanol solution $(80 \mathrm{~mL}$ 
of distilled water, $20 \mathrm{~mL}$ of methanol) by means of a magnetic stirrer within the reactor. Prior to the experiment, the mixture was dispersed by ultrasound treatment for 15 minutes, followed by purging $\mathrm{N}_{2}$ gas for 30 minutes. The amount of evolved $\mathrm{H}_{2}$ was determined by a GC5890F gas chromatograph (thermal conductivity detector, molecular sieve 5A, $99.999 \% \mathrm{~N}_{2}$ carrier).

\section{Results and discussion}

\section{Characterization of the $\mathrm{GO}$ and FePt-rGO samples}

Fig. 1 shows the nitrogen adsorption-desorption isotherms of GO and FePt-rGO, which were used to investigate the surface area and porous structure. The surface area of GO and FePt-rGO calculated by the Brunauer-Emmett-Teller (BET) theory, which explain the physical adsorption of gas molecules on a solid surface ${ }^{33}$, are 741.2 and $1018.7 \mathrm{~m}^{2} \mathrm{~g}^{-1}$, respectively.

As shown in Fig. 2a, the broad and relatively weak diffraction peak at $2 \theta=10.5^{\circ}(d=0.87 \mathrm{~nm})$, which corresponds to the typical diffraction peak of graphene oxide adsorbent, is attributed to the (002) plane $^{34}$. The $2 \theta$ values for FePt-rGO at $40.77^{\circ}$, $46.92^{\circ}, 69.30^{\circ}$, and $83.10^{\circ}$ can be indexed to diffraction planes of (111), (200), (220), and (311), respectively. The mentioned planes can be attributed to chemically disordered fcc metal nanoparti$\mathrm{cle}^{12}$. No peaks from the iron oxides were observed in the XRD data, confirming that the iron nanoparticles were not oxidized. The peak at ca. $24.32^{\circ}(2 \theta)$ is related to carbon peak of reduced graphene oxide $^{35}$.

A representative TEM image of the obtained FePt-rGO is shown in Fig. 3a. The TEM image of FePt-rGO also shows that platinum-iron nanoparticles are relatively well-dispersed on the reduced graphene oxide sheet. The mean size of FePt-rGO

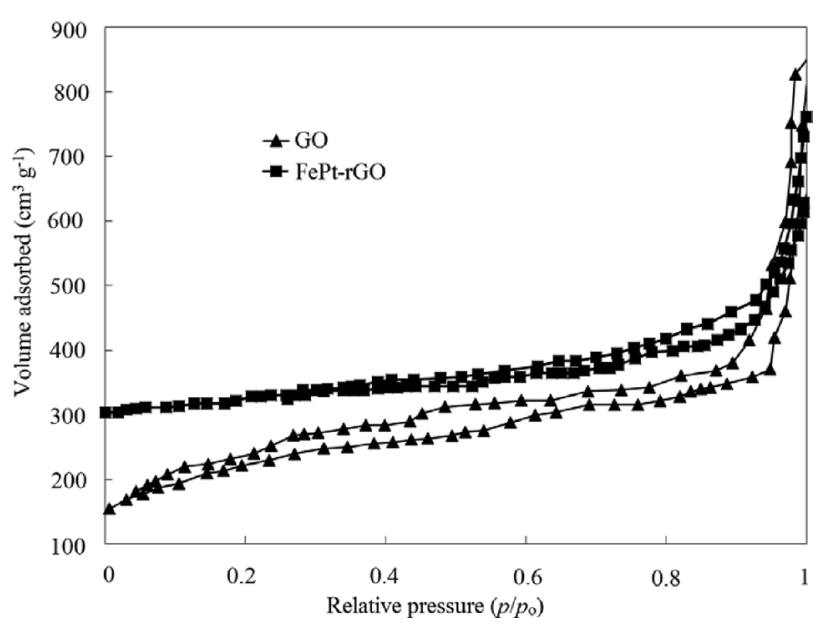

Fig. 1 - Nitrogen adsorption-desorption isotherms of $G O$ and FePt-rGO

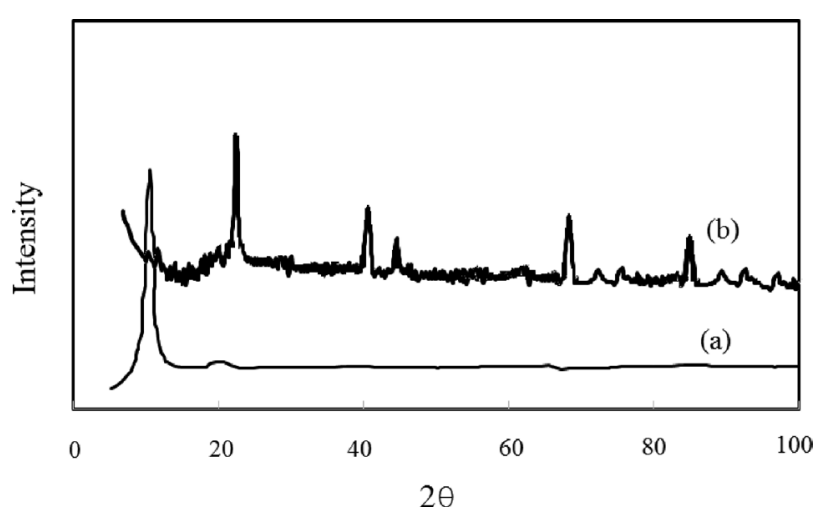

Fig. 2 - XRD pattern of (a) GO and (b) FePt-rGO

calculated from the TEM image is around $16.0 \mathrm{~nm}$. The histogram of particle size for FePt-rGO show that the size distribution is relatively narrow (Fig. $3 b)$.

Fig. 4 displays Pt $4 \mathrm{f}$ and Fe 2p X-ray photoelectron spectroscopy (XPS) spectra of FePt-rGO composites. The two characteristic peaks at $71.3 \mathrm{eV}$ $\left(\mathrm{Pt} 4 \mathrm{f}_{7 / 2}\right)$ and $74.5 \mathrm{eV}\left(\mathrm{Pt}_{4 / 2}\right)$ may be observed in
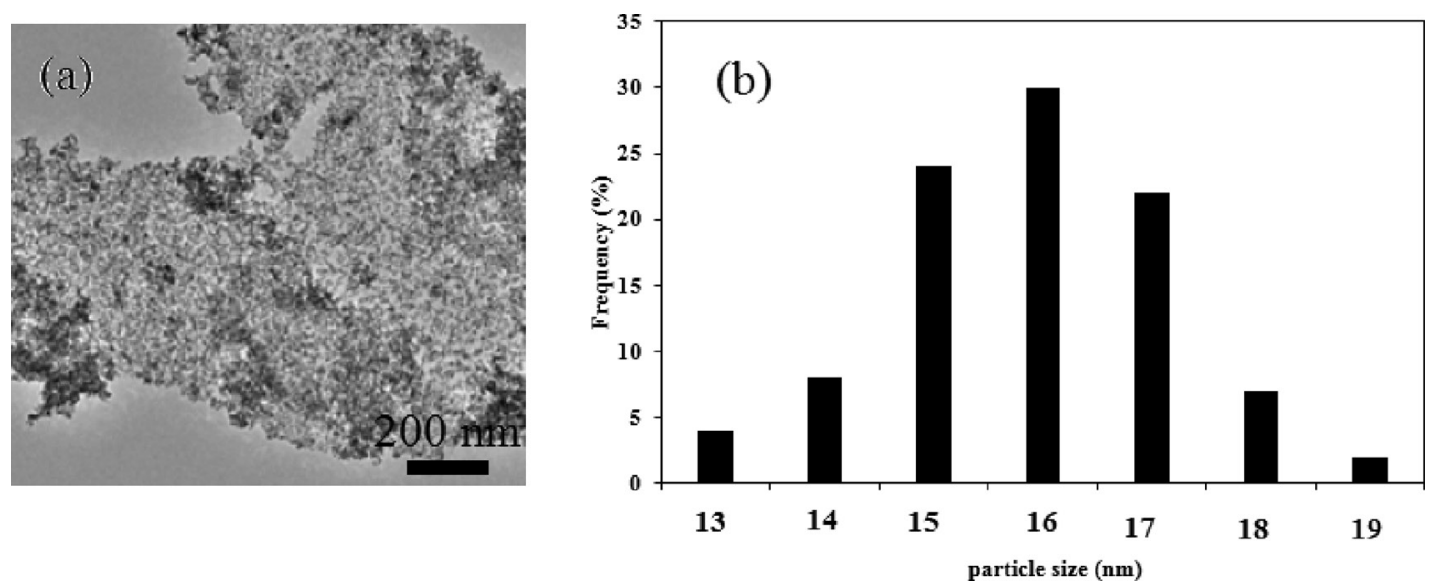

Fig. 3 - (a) TEM photographs, and (b) histogram of particle size distribution of FePt-rGO 

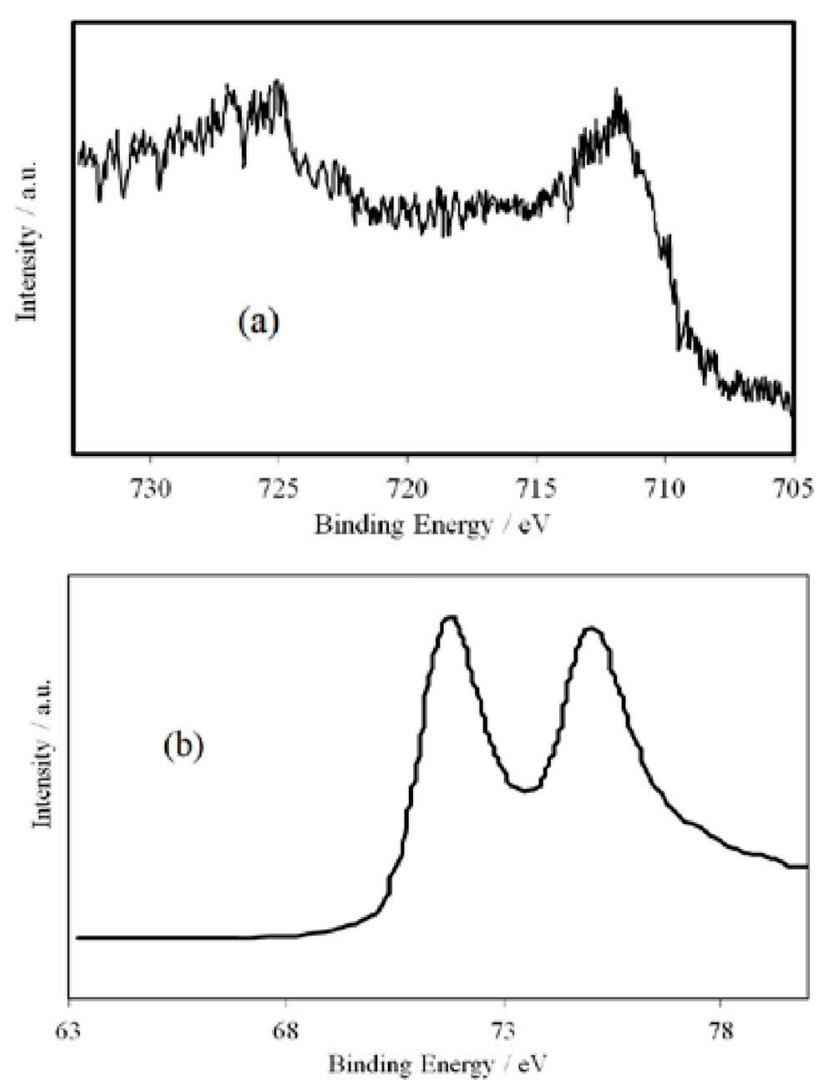

Fig. 4 - XPS spectra of Fe $2 p$ in the FePt-rGO composites and (b) XPS spectra of Pt $4 f$ in the FePt-rGO composites

Fig. 4a, confirming the formation of metallic Pt. The peaks at $711.1 \mathrm{eV}\left(\mathrm{Fe} 2 \mathrm{p}_{3 / 2}\right)$ and $725.6 \mathrm{eV}(\mathrm{Fe}$ $2 \mathrm{p}_{1 / 2}$ ) presented in Fig. $4 \mathrm{~b}$, show the existence of $\mathrm{Fe}-\mathrm{O}$ or $\mathrm{Fe}-\mathrm{OOH}$ group in FePt-rGO composites. Moreover, no signal for the $\mathrm{C}$ in the XPS is provided, which would be useful to confirm the reduction of GO.

The TGA was also performed on GO and the FePt-rGO samples to determine the structure and thermal stability of the $\mathrm{GO}$ and the FePt-rGO (Fig. 5a and Fig. 5b). GO shows two significant weight losses close to $100{ }^{\circ} \mathrm{C}$ and $500{ }^{\circ} \mathrm{C}$ with $9 \%$

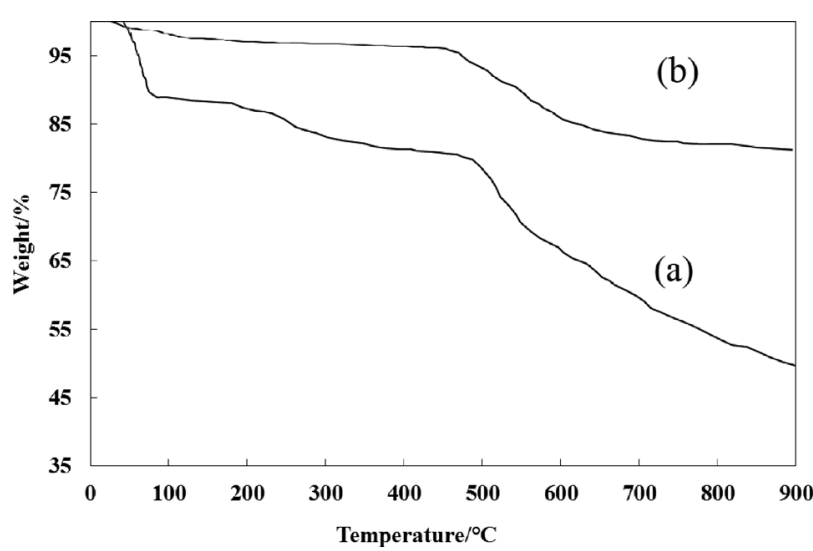

Fig. 5 - TGA curves of (a) GO and (b) FePt-rGO and $30 \%$ weight loss, respectively. They are related to the evaporation of the water molecules in the material and thermal decomposition of oxygen carrying functionalities and oxidation of carbon. The FePt-rGO shows a $2 \%$ loss below $100{ }^{\circ} \mathrm{C}$ which should be due to the removal of adsorbed water, a $3 \%$ loss at ca. $200{ }^{\circ} \mathrm{C}$ should be assigned to the decomposition of the residual oxygen containing groups, and a $13 \%$ loss from 440 to $590{ }^{\circ} \mathrm{C}$ should be associated with the pyrolysis of the carbon skeleton of reduced graphene oxide ${ }^{36}$. These results suggest that FePt-rGO is thermally stable at higher temperatures.

To investigate the optical properties, UV-Vis absorption spectra of FePt and FePt-rGO are shown in Fig. 6. It can be observed that FePt and FePt-rGO show sharp absorption edges at around $470 \mathrm{~nm}$. Fig. $6 \mathrm{~b}$ displays the plot of the transformed $\mathrm{Ku}-$ belka-Munk function versus energy of light, by which the estimated band gaps are 3.2 and $2.8 \mathrm{eV}$, corresponding to FePt and FePt-rGO, respectively. The narrow band gap of FePt-rGO nanoparticles was attributed to the interaction between $\mathrm{rGO}$ and FePt.
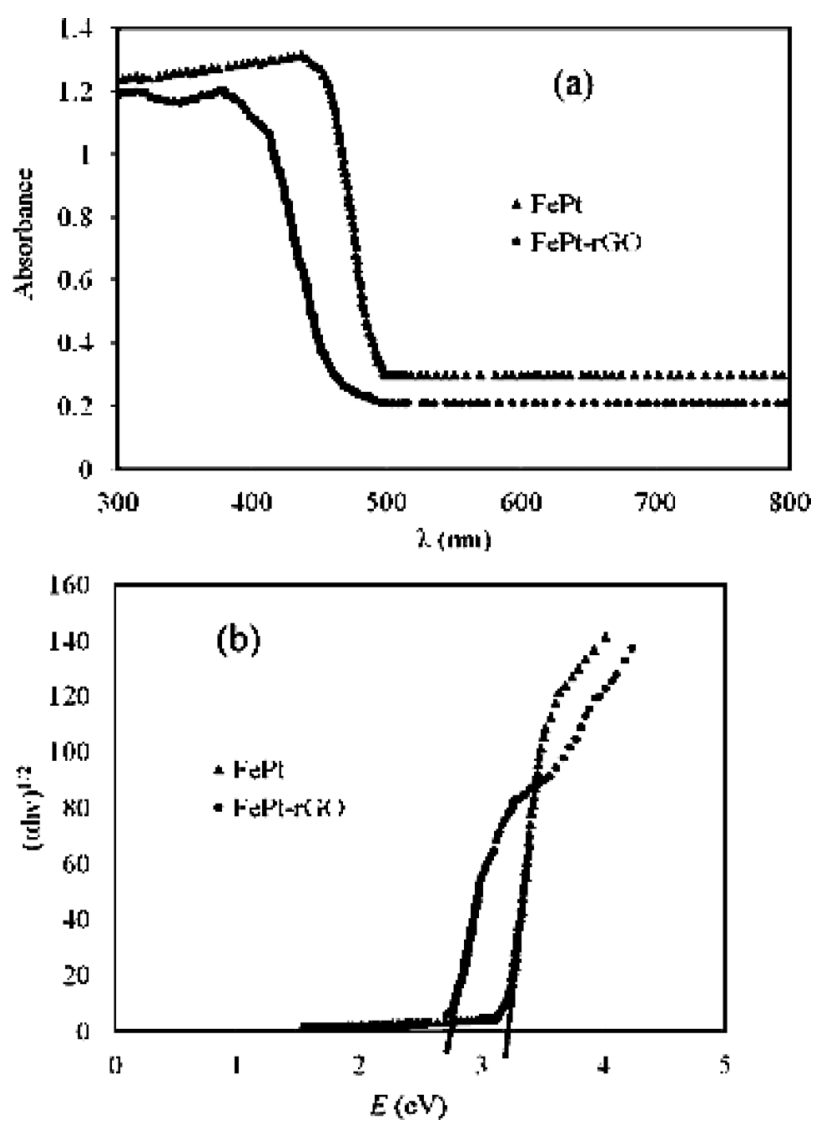

Fig. 6 - (a) UV-Vis diffuse reflectance spectra of FePt and FePt-rGO nanoparticles (b) corresponding plot of transformed Kubelka-Munk function versus the energy of the light absorbed 


\section{Photocatalytic hydrogen evolution activity and mechanism}

The hydrogen generating capability of the composite photocatalysts was investigated in methanol aqueous solution. The photocatalytic results of the reduction of water to produce $\mathrm{H}_{2}$ over FePt and FePt-rGO catalysts are shown in Fig. 7. The rate of hydrogen evolution continuously increased at the initial reaction duration, and after several hours, it reached a constant value of $125 \mu \mathrm{mol} \mathrm{g} \mathrm{g}^{-1} \mathrm{~h}^{-1}$ (Fig. 7). The total amount of $\mathrm{H}_{2}$ evolved from FePt-rGO after $6 \mathrm{~h}$ of irradiation was $890 \mu \mathrm{mol} \mathrm{g}^{-1}$, which was higher than that of FePt $\left(460 \mu \mathrm{mol} \mathrm{g}^{-1}\right)$. The higher photocatalytic activity might be attributable to good light absorption of FePt-rGO compared to FePt NPs. It is reasonable to imagine the formation of a Schottky-like barrier between the closely contacted iron and platinum NPs surface species, which would facilitate electron-hole separation, similar to the action of traditional conductive platinum co-catalysts ${ }^{37}$.

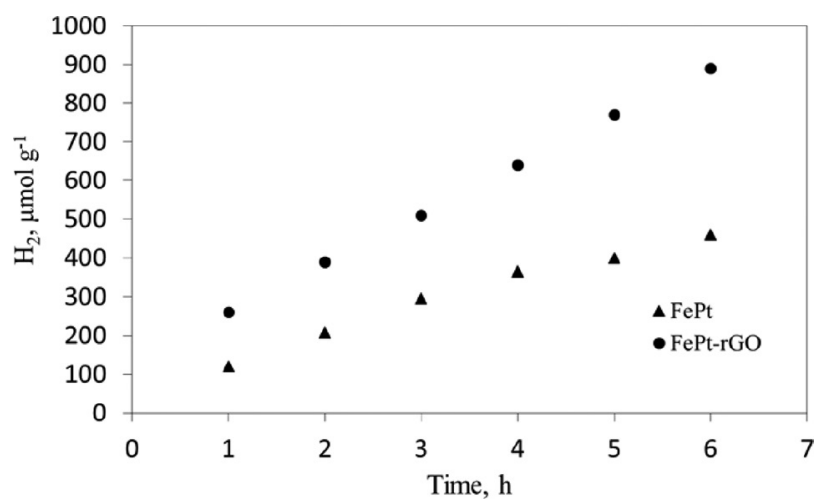

Fig. 7 - Amount of hydrogen gas produced by (a) FePt-rGO and (b) FePt NPs (Reaction conditions: $m_{\text {catalyst }}=5 \mathrm{mg}$, [methanol] $=10 \mathrm{wt} \%, \mathrm{pH}=7, \mathrm{~T}=25^{\mathrm{C}} \mathrm{C}$ )

The highest rates of $\mathrm{H}_{2}$ generation with the above amounts of nanomaterials are shown in Fig. 7. We can see a drastic increase in the amount of evolved $\mathrm{H}_{2}$ gas when FePt is used with reduced graphene oxide. This is due to the synergy effect of rGO to FePt. In the case of noble metal, such as $\mathrm{Pt}$, an electron from photoexcited iron oxide is transferred to $\mathrm{Pt}$, and then it reduces $\mathrm{H}^{+}$ion to produce $\mathrm{H}_{2}$ gas. Platinum nanoparticles loaded on the rGO surface are known to act as electron sinks. This strongly enhances the photocatalytic activity of iron oxide through the formation of a Schottky barrier (retarding the electron/hole recombination) at the FePt-rGO surface. This phenomenon appears to promote an efficient separation of holes and electrons charges carriers photo-generated under near-UV light. As a result, the interfacial charge transfer and the efficiency of the photocatalytic reaction are enhanced ${ }^{38-40}$. Platinum deposits can serve as a temporary electron chamber.

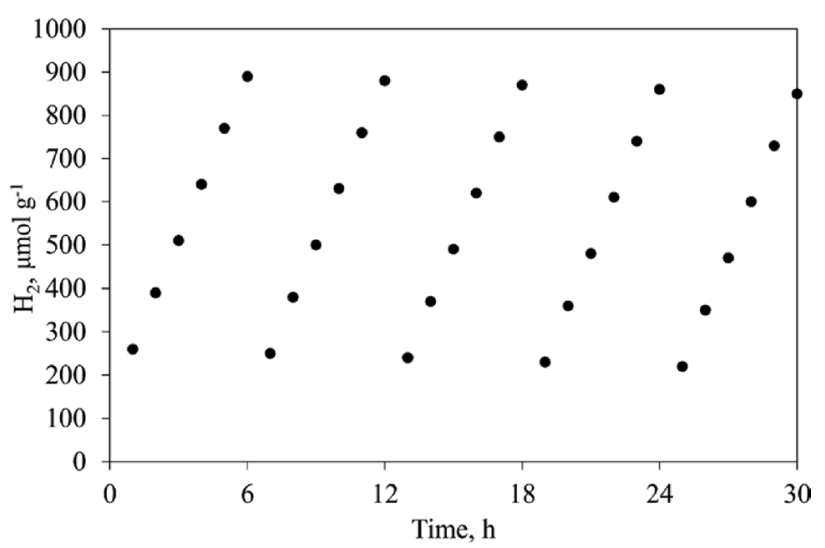

Fig. 8 - Photocatalytic $\mathrm{H}_{2}$ evolution on FePt-rGO photocatalysts with intermittent evacuation every $6 \mathrm{~h}$

Fig. 8 shows the hydrogen evolution by recycled FePt-rGO. After each cycle, the amount of hydrogen evolution from FePt-rGO remained constant. Fig. 8 shows that the photocatalytic evolution rate of hydrogen remained above $95 \%$ of the initial rate. After $30 \mathrm{~h}$ of irradiation, the system produced $850 \mu \mathrm{mol} \mathrm{g}^{-1}$ of $\mathrm{H}_{2}$ without noticeable catalyst deactivation.

\section{Conclusion}

Hydrogen evolution from water containing methanol was performed on FePt-rGO by medium-pressure Hg lamp. XPS analysis confirmed that $\mathrm{Fe}$ and $\mathrm{Pt}$ species were coordinated to reduced graphene oxides. Diffuse reflectance spectra revealed an increase in absorption with Fe and Pt NPs implying that the doping modified the electronic properties of reduced graphene oxide. The significant promotion effect of hydrogen evolution using FePt-loaded reduced graphene oxide photocatalysts was observed. The Pt and Fe NPs enhance the photocatalytic hydrogen evolution activity of FePtrGO. The hydrogen evolution of FePt-rGO was 125 $\mu$ mol $\mathrm{g}^{-1} \mathrm{~h}^{-1}$ with a maximum of $890 \mu \mathrm{mol} \mathrm{g}^{-1}$, which exceeded 1.9 times compared with FePt NPs.

\section{ACKNOWLEDGMENTS}

The author thanks The Research Council at the Azad University for financial support.

\section{References}

1. Teets, T. S., Nocera, D. G., Photocatalytic Hydrogen Production, Chem. Commun. 47 (2011) 9268. doi: http://dx.doi.org/10.1039/c1cc12390d

2. Leygraf, C., Hendewerk, M., Somorjai, G. A., Photocatalytic Production of Hydrogen from Water by a P- and N-Type Polycrystalline Iron Oxide Assembly, J. Phys. Chem. 86 (1982) 4484.

doi: http://dx.doi.org/10.1021/j100220a007 
3. Xing, C., Zhang, Y., Yan, W., Guo, L., Band Structure-Controlled Solid Solution of Photocatalyst for Hydrogen Production by Water Splitting, Int. J. Hydrogen Energy 31 (2006) 2018.

doi: http://dx.doi.org/10.1016/j.ijhydene.2006.02.003

4. Yu, D., Aihara, M., Antal, M. J., Hydrogen Production by Steam Reforming Glucose in Supercritical Water, Energy Fuels 7 (1993) 574 doi: http://dx.doi.org/10.1021/ef00041a002

5. Barbir, F., PEM Electrolysis for Production of Hydrogen from Renewable Energy Sources, Sol. Energ. 78 (2005) 661.

doi: http://dx.doi.org/10.1016/j.solener.2004.09.003

6. Kim, J., Monllor-Satoca, D., Choi, W., Simultaneous Production of Hydrogen with the Degradation of Organic Pollutants Using $\mathrm{TiO}_{2}$ Photocatalyst Modified with Dual Surface Components, Energy. Environ. Sci. 5 (2012) 7647. doi: http://dx.doi.org/10.1039/c2ee21310a

7. Sathre, R., Scown, C. D., Morrow, W. R., Stevens, J. C., Sharp, I. D., Ager, J. W., Walczak, K., Houle, F. A., Greenblatt, J. B., Life-Cycle Net Energy Assessment of LargeScale Hydrogen Production Via Photoelectrochemical Water Splitting, Energy. Environ. Sci. 7 (2014) 3264. doi: http://dx.doi.org/10.1039/C4EE01019A

8. Lingampalli, S. R., Gautam, U. K., Rao, C. N. R., Highly Efficient Photocatalytic Hydrogen Generation by Solution-Processed $\mathrm{ZnO} / \mathrm{Pt} / \mathrm{CdS}, \quad \mathrm{ZnO} / \mathrm{Pt} / \mathrm{Cd} 1-\mathrm{xZnxS}$ and $\mathrm{ZnO} / \mathrm{Pt} / \mathrm{CdS} 1-\mathrm{xSex}$ Hybrid Nanostructures, Energy Environ. Sci. 6 (2013) 3589.

doi: http://dx.doi.org/10.1039/c3ee42623h

9. Natali, M., Luisa, A., Iengo, E., Scandola, F., Efficient Photocatalytic Hydrogen Generation from Water by a Cationic Cobalt(Ii) Porphyrin, Chem. Commun. 50 (2014) 1842. doi: http://dx.doi.org/10.1039/c3cc48882a

10. Jing, D., Guo, L., Zhao, L., Zhang, X., Liu, H., Li, M., Shen, S., Liu, G., Hu, X., Zhang, X., Zhang, K., Ma, L., Guo, P., Efficient Solar Hydrogen Production by Photocatalytic Water Splitting: From Fundamental Study to Pilot Demonstration, Int. J. Hydrogen Energy 35 (2010) 7087. doi: http://dx.doi.org/10.1016/j.ijhydene.2010.01.030

11. Ni, M., Leung, M. K. H., Leung, D. Y. C., Sumathy, K., A Review and Recent Developments in Photocatalytic Water-Splitting Using for Hydrogen Production, Renew. Sustainable Energy Rev. 11 (2007) 401. doi: http://dx.doi.org/10.1016/j.rser.2005.01.009

12. Zhang, J., Yang, H., Yang, K., Fang, J., Zou, S., Luo, Z., Wang, H., Bae, I.-T., Jung, D. Y., 'Monodisperse $\mathrm{Pt}_{3} \mathrm{Fe}$ Nanocubes: Synthesis, Characterization, Self-Assembly, and Electrocatalytic Activity', Adv. Funct. Mater. 20 (2010) 3727.

doi: http://dx.doi.org/10.1002/adfm.201000679

13. Chen, X., Shen, S., Guo, L. Mao, S. S., Semiconductor-Based Photocatalytic Hydrogen Generation, Chem. Rev. 110 (2010) 6503. doi: http://dx.doi.org/10.1021/cr1001645

14. Aharon-Shalom, E., Heller, A., Efficient $\mathrm{p}-\mathrm{InP}(\mathrm{Rh}-\mathrm{H}$ alloy) and $\mathrm{p}-\mathrm{InP}(\mathrm{Re}-\mathrm{H}$ alloy) Hydrogen Evolving Photocathodes, J. Electrochem. Soc. 129 (1982) 2865. doi: http://dx.doi.org/10.1149/1.2123695

15. Gadiou, R., Saadallah, S.-E., Piquero, T., David, P., Parmentier, J., Vix-Guterl, C., The Influence of Textural Properties on the Adsorption of Hydrogen on Ordered Nanostructured Carbons, Microporous Mesoporous Mater. 79 (2005) 121. doi: http://dx.doi.org/10.1016/j.micromeso.2004.10.034
16. Armandi, M., Bonelli, B., Otero Areán, C., Garrone, E. Role of Microporosity in Hydrogen Adsorption on Templated Nanoporous Carbons, Microporous Mesoporous Mater. 112 (2008) 411 doi: http://dx.doi.org/10.1016/j.micromeso.2007.10.017

17. Nguyen, N. T., Yoo, J., Altomare, M., Schmuki, P., 'Suspended" Pt Nanoparticles over $\mathrm{TiO}_{2}$ Nanotubes for Enhanced Photocatalytic $\mathrm{H}_{2}$ Evolution, Chem. Commun. 50 (2014) 9653. doi: http://dx.doi.org/10.1039/C4CC04087B

18. Zhu, Y., Ling, Q., Liu, Y., Wang, H., Zhu, Y., Photocatalytic $\mathrm{H}_{2}$ Evolution on $\mathrm{MoS}_{2}-\mathrm{TiO}_{2}$ Catalysts Synthesized Via Mechanochemistry, Phys. Chem. Chem. Phys. 17 (2015) 933. doi: http://dx.doi.org/10.1039/C4CP04628E

19. Inagaki, M., Kojin, F., Tryba, B., Toyoda, M., Carbon-Coated Anatase: The Role of the Carbon Layer for Photocatalytic Performance, Carbon 43 (2005) 1652. doi: http://dx.doi.org/10.1016/j.carbon.2005.01.043

20. Mukherji, A., Seger, B., Lu, G. Q., Wang, L., Nitrogen Doped $\mathrm{Sr}_{2} \mathrm{Ta}_{2} \mathrm{O}_{7}$ Coupled with Graphene Sheets as Photocatalysts for Increased Photocatalytic Hydrogen Production, ACS Nano 5 (2011) 3483. doi: http://dx.doi.org/10.1021/nn102469e

21. Wang, H., Yuan, X., Wu, Y., Huang, H., Peng, X., Zeng, G., Zhong, H., Liang, J., Ren, M. M., Graphene-Based Materials: Fabrication, Characterization and Application for the Decontamination of Wastewater and Wastegas and Hydrogen Storage/Generation, Adv. Colloid Interface Sci. 195-196 (2013) 19 . doi: http://dx.doi.org/10.1016/j.cis.2013.03.009

22. Shin, H.-J., Choi, W. M., Choi, D., Han, G. H., Yoon, S.-M., Park, H.-K., Kim, S.-W., Jin, Y. W., Lee, S. Y., Kim, J. M., Choi, J.-Y., Lee, Y. H., Control of Electronic Structure of Graphene by Various Dopants and Their Effects on a Nanogenerator, J. Am. Chem. Soc. 132 (2010) 15603. doi: http://dx.doi.org/10.1021/ja105140e

23. Rajesh, U. C., Wang, J., Prescott, S., Tsuzuki, T., Rawat, D. S., rGO/ZnO Nanocomposite: An Efficient, Sustainable, Heterogeneous, Amphiphilic Catalyst for Synthesis of 3-Substituted Indoles in Water, ACS Sustainable Chem. Eng. 3 (2014) 9. doi: http://dx.doi.org/10.1021/sc500594w

24. Qu, Y., Gao, Y., Kong, F., Zhang, S., Du, L., Yin, G., Pt-RGO-TiO Nanocomposite by Uv-Photoreduction Method as Promising Electrocatalyst for Methanol Oxidation, Int. J. Hydrogen Energy 38 (2013) 12310. doi: http://dx.doi.org/10.1016/j.ijhydene.2013.07.038

25. Li, P., Zhou, Y., Li, H., Xu, Q., Meng, X., Wang, X., Xiao, M., Zou, Z., All-Solid-State Z-Scheme System Arrays of $\mathrm{Fe}_{2} \mathrm{~V}_{4} \mathrm{O}_{13} / \mathrm{Rgo} / \mathrm{Cds}$ for Visible Light-Driving Photocatalytic $\mathrm{CO}_{2}$ Reduction into Renewable Hydrocarbon Fuel, Chem. Commun. 51 (2015) 800. doi: http://dx.doi.org/10.1039/C4CC08744E

26. Li, J., Wang, G., Wang, J., Miao, S., Wei, M., Yang, F., Yu, L., Bao, X., Architecture of PtFe/C Catalyst with High Activity and Durability for Oxygen Reduction Reaction, Nano Res. 7 (2014) 1519. doi: http://dx.doi.org/10.1007/s12274-014-0513-0

27. Thoi, V. S., Usiskin, R. E., Haile, S. M., Platinum-Decorated Carbon Nanotubes for Hydrogen Oxidation and Proton Reduction in Solid Acid Electrochemical Cells, Chem. Sci. 6 (2015) 1570. doi: http://dx.doi.org/10.1039/C4SC03003F

28. Kuyunko, N. S., Kushch, S. D., Muradyan, V. E., Volodin, A. A., Torbov, V. I., Tarasov, B. P., Pt Nanoclusters on Carbon Nanomaterials for Hydrogen Fuel Cells, in Hydrogen Materials Science and Chemistry of Carbon Nanomaterials, Springer Netherlands, 2007, pp. 213-18. doi: http://dx.doi.org/10.1007/978-1-4020-5514-0 26 
29. Wakabayashi, N., Takeichi, M., Uchida, H., Watanabe, M., Temperature Dependence of Oxygen Reduction Activity at $\mathrm{Pt}-\mathrm{Fe}, \mathrm{Pt}-\mathrm{Co}$, and Pt-Ni Alloy Electrodes, J. Phys. Chem. B 109 (2005) 5836.

doi: http://dx.doi.org/10.1021/jp046204+

30. Sumida, K., Horike, S., Kaye, S. S., Herm, Z. R., Queen, W. L., Brown, C. M., Grandjean, F., Long, G. J., Dailly, A., Long, J. R., Hydrogen Storage and Carbon Dioxide Capture in an Iron-Based Sodalite-Type Metal-Organic Framework (Fe-BTT) Discovered Via High-Throughput Methods, Chem. Sci. 1 (2010) 184. doi: http://dx.doi.org/10.1039/c0sc00179a

31. Hummers, W. S., Offeman, R. E., Preparation of Graphitic Oxide, J. Am. Chem. Soc. 80 (1958) 1339. doi: http://dx.doi.org/10.1021/ja01539a017

32. Chen, D., Zhao, X., Chen, S., $L i, H ., F u, X$., Wu, Q., Li, S., $L i, \quad Y$., Su, B.-L., Ruoff, R. S., One-Pot Fabrication of $\mathrm{FePt} /$ Reduced Graphene Oxide Composites as Highly Active and Stable Electrocatalysts for the Oxygen Reduction Reaction, Carbon 68 (2014) 755. doi: http://dx.doi.org/10.1016/j.carbon.2013.11.064

33. Brunauer, S., Emmett, P. H., Teller, E., Adsorption of Gases in Multimolecular Layers, J. Am. Chem. Soc. 60 (1938) 309.

doi: http://dx.doi.org/10.1021/ja01269a023

34. Zhu, Y., Stoller, M. D., Cai, W., Velamakanni, A., Piner R. D., Chen, D., Ruoff, R. S., Exfoliation of Graphite Oxide in Propylene Carbonate and Thermal Reduction of the Resulting Graphene Oxide Platelets, ACS Nano. 4 (2010) 1227.

doi: http://dx.doi.org/10.1021/nn901689k
35. Qiu, J.-D., Wang, G.-C., Liang, R.-P., Xia, X.-H., Yu, H.-W., Controllable Deposition of Platinum Nanoparticles on Graphene as an Electrocatalyst for Direct Methanol Fuel Cells, J. Phys. Chem. C. 115 (2011) 15639. doi: http://dx.doi.org/10.1021/jp200580u

36. Liu, J., Tao, L., Yang, W., Li, D., Boyer, C., Wuhrer, R., Braet, F., Davis, T. P., Synthesis, Characterization, and Multilayer Assembly of $\mathrm{pH}$ Sensitive Graphene-Polymer Nanocomposites, Langmuir 26 (2010) 10068. doi: http://dx.doi.org/10.1021/la1001978

37. Williams, P. A., Ireland, C. P., King, P. J., Chater, P. A., Boldrin, P., Palgrave, R. G., Claridge, J. B., Darwent, J. R., Chalker, P. R., Rosseinsky, M. J., Atomic Layer Deposition of Anatase $\mathrm{TiO}_{2}$ Coating on Silica Particles: Growth, Characterization and Evaluation as Photocatalysts for Methyl Orange Degradation and Hydrogen Production, J. Mater. Chem. 22 (2012) 20203. doi: http://dx.doi.org/10.1039/c2jm33446a

38. Kandiel, T. A., Dillert, R., Bahnemann, D. W., Enhanced Photocatalytic Production of Molecular Hydrogen on $\mathrm{TiO}_{2}$ Modified with Pt-Polypyrrole Nanocomposites, Photochem. Photobiol. Sci. 8 (2009) 683. doi: $\mathrm{http} / / / \mathrm{dx}$.doi.org/10.1039/b817456c

39. Riassetto, D., Holtzinger, C., Messaoud, M., Briche, S., Berthomé, G., Roussel, F., Rapenne, L., Langlet, M., Mechanisms Involved in the Platinization of Sol-Gel-Derived $\mathrm{TiO}_{2}$ Thin Films, J. Photochem. Photobiol. A. 202 (2009) 214. doi: http://dx.doi.org/10.1016/j.jphotochem.2008.11.023

40. Lee, J., Choi, W., Photocatalytic Reactivity of Surface Platinized $\mathrm{TiO}_{2}$ : Substrate Specificity and the Effect of Pt Oxidation State, J. Phys. Chem. B 109 (2005) 7399. doi: http://dx.doi.org/10.1021/jp044425+ 
